\title{
De tragédia a solução: a atualidade teórica e empírica dos recursos comuns no Brasil
}

From tragedy to solution: the theoretical and empirical relevance of commons in Brazil

\begin{abstract}
This article provides a recent update on common-pool resource studies in Brazil, presenting how the subject is evolving, both in theory and in practice. Firstly, a theoretical review is provided, in order to present the most recent academic proposals in this field. Next, the concept of traditional commons resources is overviewed, highlighting its characteristics and its main divisions. A survey of major Brazilian empirical research about commons is presented. Next, the concept of new commons resources is introduced, bringing forward how this can supply a theoretical solution for several contemporary Brazilian and international problems. It can be seen that not only has the amount of research in the area increased, but the concept of commons itself has expanded to encompass new coordination problems, given that individuals increasingly see contemporary problems as collective ones.
\end{abstract}

\section{Keywords}

Common-pool resources, Traditional commons, New commons, Self-governance.

JEL Codes Q57, 017, D02.

\author{
Mateus Cesar (1) \\ Ivette Luna (2) \\ Ellie Perkins ${ }^{(3)}$ \\ (1) Universidade Estadual de Campinas \\ (2) Universidade Estadual de Campinas \\ (3) York Univeristy
}

\section{Resumo}

Este artigo tem como objetivo apresentar a atualidade do estudo dos recursos comuns no Brasil, expondo como o tema evoluiu, tanto na teoria quanto na prática. Primeiramente, faz-se uma revisão teórica sobre o tema, de modo a apresentar ao leitor as proposições acadêmicas mais recentes na área. Em seguida, expõe-se o conceito de "recursos comuns tradicionais", destacando suas características e principais divisões. Em seguida, é feito um levantamento de relevantes pesquisas brasileiras que lidaram com a questão empiricamente. Finalmente, apresenta-se o conceito de "novos recursos comuns" e de que modo essa categoria pode servir como solução teórica a diversos problemas contemporâneos. De maneira geral, percebe-se que o próprio conceito de recursos comuns se expandiu nos últimos anos, de forma a abranger o estudo de diferentes falhas de coordenação entre agentes, numa realidade na qual os problemas atuais são cada vez mais vistos como problemas coletivos.

\section{Palavras-chave}

Recursos comuns, recursos comuns tradicionais, novos recursos comuns, autogovernança.

Códigos JEL Q57, 017, D02. 


\section{Introdução}

O estudo dos recursos comuns evoluiu de maneira quantitativa e qualitativa desde a publicação de Governing the Commons (Ostrom, 1990), obra que marcou a problematização sobre os recursos comuns no mundo, concedendo à autora do livro o Prêmio Nobel de Economia em 2009. Para Elinor Ostrom, através do uso da comunicação e de relações de confiança, a gestão comunitária seria uma solução eficiente ao problema dos recursos comuns, apresentando-se como uma estratégia mais rápida e barata para solucionar as falhas de coordenação do que as maximizações produzidas por uma ação racional convencional. A cooperação, o monitoramento e o compartilhamento seriam, dessa forma, uma terceira via para as soluções de mercado ou de Estado, propostas por Hardin (1968).

Atualmente, uma vasta corrente de cientistas está articulada e comprometida com o estudo dos recursos comuns. Chega-se a falar em um "movimento acadêmico" em prol do tema, uma nova forma de enxergar os problemas de coordenação contemporâneos (Hess, 2008). Esse movimento não só se preocupa com a produção acadêmica per se como também se articula para sistematizar e divulgar os trabalhos já realizados na área, através de congressos internacionais capitaneados por uma rede vibrante de atores e instituições.

Com esse grande esforço de articulação acadêmica, materializado através da inserção de cientistas das mais diversas searas do conhecimento, o próprio conceito de recurso comum se expandiu e passou a englobar outras discussões contemporâneas. Se antigamente o foco de estudo estava relacionado a recursos naturais - a) rivais e não exclusivos, b) situados em sistemas socioambientais de longa duração, e c) de pequena escala -, hoje em dia, o estudo dos recursos comuns abraça outros temas que perfazem esferas mais intangíveis e urbanas, como o compartilhamento de dados em rede de internet e problemas de coordenação no trânsito.

Dessa maneira, pode-se falar na existência de estudos atuais relacionados a: a) recursos comuns tradicionais, e a b) novos recursos comuns (FES, 2011; Hess 2008). Ambas as maneiras de se enxergar a problemática têm apresentado produção e importância crescente no cenário de publicações internacionais, embora o último campo de pesquisa ainda possua alguns conceitos indefinidos. 
Com a intenção de entender melhor esse avanço, o presente artigo tem por objetivo apresentar a realidade teórica e empírica dos recursos comuns no Brasil à luz da autogovernança. Para isso, o texto inicia-se fazendo uma revisão teórica do assunto. Abordam-se as contribuições mainstream a respeito da temática, bem como as contribuições de Elinor Ostrom e de outros autores contemporâneos. Em seguida, apresenta-se o conceito de "recursos comuns tradicionais", elencando casos brasileiros de gestão desses recursos e identificando dificuldades enfrentadas pelos agentes que os gerem. Apresenta-se também uma tabela com os principais estudos na área, fazendo um panorama geral sobre o atual estado da literatura referente aos recursos comuns no país.

Por último, introduz-se o conceito de "novos recursos comuns", explicitando suas subdivisões e, da mesma forma como feito com o conceito anterior, elenca-se uma série de estudos na área, apontando as vantagens e limitações desse novo modo de enxergar os bens comuns. Percebe-se que, apesar de recente no Brasil, o tema vem ganhando cada vez mais abrangência.

O que outrora estava restrito a estudos ambientais de conservação da natureza ou estudos sociais sobre comunidade tradicionais, hoje se mistura com o político e ganha força nacional como uma forma de reivindicar direitos coletivos e proteger recursos não apenas ambientais. Dessa forma, há forte correlação entre o atual campo político de luta por direitos no Brasil e o estudo acadêmico sobre recursos comuns, materializado em associações/cooperativas e nas ações de pesquisa em prol da defesa desses recursos.

\section{A teoria por trás dos recursos comuns}

Para entender a problemática dos recursos comuns e a proposta da autogovernança apresentada por Elinor Ostrom, é necessário antes compreender alguns modelos que serviram de base para a formulação teórica dessa problemática. Refere-se aqui a um grande aparato neoclássico com proposições bem definidas. Segundo Ostrom, os três principais modelos utilizados para sustentar a visão mainstream a respeito da gestão dos recursos comuns foram: a própria tragédia dos comuns (Hardin, 1968), o jogo do dilema do prisioneiro (Tucker, 1983) e a lógica da ação coletiva (Olson, 1965). 
A "tragédia" recuperava a ideia da finitude dos recursos, uma vez que a soma de unidades extraídas individualmente de um sistema seria maior do que a capacidade máxima de extração dele como um todo, levando à sua escassez. O dilema dos prisioneiros, por sua vez, apontava para a inevitabilidade da não cooperação entre agentes dentro de um jogo. Por último, a lógica da ação coletiva afirmava que o indivíduo só agiria coletivamente se esta fosse uma estratégia mais vantajosa para ele próprio. Juntos, esses três modelos delatavam a incapacidade de os agentes cooperarem uns com os outros e resolverem por si só o problema dos comuns.

O principal modelo entre estes foi elaborado por Garret Hardin, através de seu artigo "The Tragedy of the Commons", quando este defendeu que a gestão de recursos comuns por uso compartilhado ou pela propriedade coletiva seria insustentável, já que as pessoas, agindo de forma racional e egoísta, tenderiam a esgotá-los (Santana; Fontes, 2010). Essa tragédia, causada pela própria racionalidade do agente econômico, só poderia ser solucionada através da presença de um instrumento coercitivo externo capaz de regular a ação humana individual.

O pensamento de Hardin se apoiava na crença de que o regime de propriedade comum favorecia a sobre-exploração dos insumos naturais e de que o crescimento da população mundial agravaria ainda mais essa pressão (Ballesteros; Alcofrado, 2009). Dessa maneira, a solução para isso passaria pela intervenção do mercado (privatização dos recursos) ou do Estado (estatização), que seriam as instituições responsáveis por sua regulação. Esse é o princípio básico do modelo de Hardin que foi reafirmado por inúmeros outros cientistas (Dales, 1968; Clark, 1976; Dasgputa; Heal, 1979), e hoje é material didático utilizado em quase todos os livros de microeconomia.

É certo que outros relevantes modelos foram formulados e mais outros vêm sendo elaborados pela economia ambiental para lidar com a problemática. É o caso do problema da negociação de direitos de propriedade proposto por Ronald Coase (1937) e suas adaptações mais recentes. Segundo esse teorema, se os agentes afetados por problemas de alocação pudessem negociar direitos de propriedade (privados), poderiam chegar a um estado ótimo de alocação de seus recursos no sentido de Pareto.

De modo geral, os modelos atuais de economia neoclássica ambiental que tratam a questão são modelos dinâmicos de equilíbrio parcial (Mueller, 2007), assentados na contribuição de Hotelling (1931), Coase (1937), assim como na contribuição de outros autores tais quais 
Simon Kuznets e Pareto. Em regra, os modelos são extensões de teoremas básicos da teoria do bem-estar social e dos direitos de propriedade bem definidos (Mueller, 2007).

Por outro lado, posicionamentos como o apresentado pelo Prêmio Nobel de Economia Joseph Stiglitz corroboram a existência da complexidade das decisões numa sociedade (que nem sempre são meras somas de decisões individuais), entendendo que mecanismos de resolução de problemas nem sempre precisam passar por contratos formais (Stiglitz, 1974). O monitoramento dos pares proposto por outros autores (Kandel; Lazear, 1992) é uma importante saída para isso, pois serve como um instrumento de diminuição do comportamento free rider.

Pela proximidade dos pares (que facilita o monitoramento em termos de tempo e espaço) e pela busca de ser aceito dentro da comunidade (não burlando regras e correspondendo às expectativas de outros agentes), o monitoramento local tende a ser mais eficiente.

Mais recentemente, Stiglitz voltou a falar sobre os "problemas que o setor privado é incapaz de resolver", sobretudo porque ele próprio os cria, bem como nos perigos do individualismo excessivo. $O$ autor aposta nas cooperativas como uma maneira de impulsionar o desenvolvimento para rumos mais inclusivos e solidários, em detrimento da economia individualista vigente, acreditando que "as cooperativas e a economia social provêm um terceiro pilar chave para resolução destes problemas globais". Ele acredita que "há formas alternativas de organização que precisam ser discutidas que não são uma mera questão de mercado versus estado" (VOINEA, 2016, tradução nossa).

É importante ressaltar que outras vertentes da economia (que não só a pura microeconomia) vêm trabalhando para tentar superar a tragédia. Destaca-se a importância da economia experimental, que vai a campo testar empiricamente a validade das hipóteses econômicas na teoria dos jogos, realizando inúmeros tipos de jogos entre agentes, assim como as vertentes como psicologia econômica e a sociologia econômica, que também apresentam interessantes contribuições ao tema. Por hora, vamos focar na análise dos recursos comuns a partir da metodologia descrita por Ostrom, a ser melhor exposta através de seus oito princípios institucionais.

Após inúmeras pesquisas, foram encontradas oito semelhanças institucionais nos estudos de caso sobre recursos comuns que se mostraram sustentáveis sem a intervenção de atores externos: quanto mais desses prin- 
cípios estavam presentes na comunidade, maior era a chance de sucesso. Nas palavras da autora, "bens comuns de pequena escala caracterizados por muitos destes princípios são mais propensos a ter sucesso do que outros que são caracterizados por um número menor" (Ostrom, 1999, p. 6). Os princípios são explicitados na Tabela 1 e explicados a seguir.

\section{Tabela 1 Oito princípios presentes em casos de sucesso}

\begin{tabular}{ll}
\hline 1) & Limites claramente definidos \\
\hline 2) & Regras de apropriação e provisão coerentes com as condições locais \\
\hline 3) & Arranjos de escolha coletiva \\
\hline 4) & Supervisão \\
\hline 5) & Sanções graduais \\
\hline 6) & Mecanismos para a resolução de conflitos \\
\hline 7) & Reconhecimento mínimo de direitos de organização \\
\hline 8) & Rede de Instituições \\
\hline
\end{tabular}

Fonte: Ostrom, 1990.

1) Limites claramente definidos: Deve-se identificar quais os indivíduos ou famílias têm direitos para extrair os recursos assim como definir claramente quais são os limites físicos destes. A definição dos limites do recurso comum e a especificação de quem irá extraí-lo podem ser considerados os primeiros passos para se organizar uma ação coletiva. Sem essas informações, não se sabe o que (a magnitude do bem) e para quem (usuários e suas cotas de extração) o estudo valerá.

2) Regras de apropriação e provisão coerentes com as condições locais: As regras de apropriação que restringem o tempo, o lugar, a tecnologia e a quantidade de unidades de recurso se relacionam com as condições locais e com as regras de provisão que exigem trabalho, material, dinheiro ou ambos. Isso significa dizer que cada sistema de recurso tem sua especificidade e deve se adequar às condições locais. Por mais próximo que dois ou vários sistemas estejam e por mais parecidos que sejam, é necessário entender suas singularidades e formular ações a partir delas, observando suas necessidades específicas.

3) Arranjos de eleição coletiva: Todos os indivíduos afetados pelas regras operativas podem participar de sua construção e modificação. É importante que os usuários participem efetivamente da construção das regras a serem seguidas no local e se comprometam de antemão a cooperar com elas. 
4) Supervisão: Os supervisores que fazem a vigilância das regras e do comportamento dos apropriadores ou são os próprios apropriadores ou são pessoas designadas para isso previamente. Através da eleição de monitores ou gestores-chefe de um determinado sistema de recursos comuns haveria um mecanismo onipresente de fiscalização e cuidado com os recursos que uma gestão verticalizada jamais poderia proporcionar.

5) Sanções graduais: Os apropriadores que violam as regras operativas recebem sanções graduais, dependendo da gravidade e do contexto da infração. Não vale a pena aplicar uma pena tão severa a um usuário que cometeu infração uma única vez a ponto de fazer com que ele desista do sistema. Sendo assim, pode-se haver perdão para descumprimentos eventuais ou frutos de emergências. Essa flexibilidade se dá, porque punir tudo acaba por deslegitimar o sistema. A autora diz que quanto maior for a taxa de infração dentro de uma comunidade, mais os usuários tendem a não cooperar de maneira geral, pois percebem que todos estão agindo de maneira não cooperativa e acabam por agir assim também.

6) Mecanismos para a resolução de conflitos: Os apropriadores têm acesso rápido a instâncias locais para resolver conflitos a baixo custo. Como os indivíduos têm que obedecer às regras durante um largo período, deve existir um mecanismo barato e rápido para discutir e resolver os problemas gerados na comunidade. As regras são passíveis de várias interpretações e alguns usuários podem se valer desse artefato para abusar de um direito ou agirem segundo o efeito carona, beneficiando-se do trabalho de outros. Para dar credibilidade e perpetuar o sistema, sobretudo no que diz respeito à confiança nas instituições envolvidas, a presença de um mecanismo justo e imparcial para resolução de conflitos é de suma importância.

7) Reconhecimento minimo de direitos de organização: Os direitos dos apropriadores para construir suas próprias instituições devem ser reconhecidos por autoridades externas como o Estado. Fala-se aqui em reconhecer e dar autonomia à autogovernança. Quando há a intervenção estatal ou de outra instituição nas regras já estabelecidas, a autogovernança perde sua autoridade e acaba fragilizada.

8) Rede de instituições: Ostrom reafirma a necessidade de respeitar as instituições já existentes no local. Isso porque, com o crescimento dos usuários e o acirramento da tragédia dos comuns, o poder público ou o mercado costumam chegar para normatizar e tentar resolver o problema com novas regras. Não percebem, entretanto, que podem estar prejudi- 
cando a autogovernança, desperdiçando muito conhecimento já adquirido pelo sistema.

Percebeu-se que, nos casos em que o sistema deu certo, além de princípios institucionais, Ostrom conseguiu encontrar algumas semelhanças de comportamento entre os agentes apropriadores. As semelhanças encontram-se dispostas na Tabela 2, a seguir:

\section{Tabela 2 Comportamento dos usuários em um sistema bem-sucedido}

A maioria dos apropriadores compartilha o juízo comum de que serão prejudicados se não adotam uma regra alternativa

A maioria dos apropriadores se verá afetada de maneira similar pelas mudanças propostas nas regras

A maioria dos apropriadores valora altamente as atividades de continuidade deste desse bem comum, em outras palavras, têm taxas de desconto baixas

Os apropriadores compartilham normas generalizadas de reciprocidade e confiam que possam usá-las como capital social

0 grupo de apropriadores no do bem comum é relativamente pequeno e estável

Fonte: Ostrom, 1990 , p. 331-338.

Portanto, podemos encontrar interessantes padrões no que diz respeito: a) à quantidade de apropriadores, b) às suas reações frente às regras, e c) ao valor que dão à sustentabilidade do bem.

Nas comunidades que obtiveram sucesso com a autogovernança, Elinor percebeu que os indivíduos: a) se comunicavam repetidamente, b) aprendiam em quem confiar, c) percebiam as repercussões de suas ações sobre os demais e sobre os bens comuns, e d) organizavam-se para obter proveitos e evitar danos. Isso porque, quando os indivíduos convivem muito tempo nas mesmas condições e elaboram padrões de reciprocidade, eles podem se beneficiar do capital social criado (Ostrom, 1990).

Os resultados na autogovernança são melhores quando os usuários prezam pela sustentabilidade futura do recurso e quando este gera valores para os apropriadores (Ostrom, 1999). Isso porque os usuários que dependem do bem comum para sua subsistência são mais propensos a perceber os benefícios do uso racional do recurso. Eles se identificam com a terra e prezam por sua manutenção de uma maneira que nem o Estado nem o mercado são capazes (questão da taxa de desconto).

A respeito do quarto tópico presente na Tabela 2, o da confiança, é 
importante salientar que "sem supervisão não se pode ter compromissos confiáveis, sem compromissos confiáveis não há nenhuma razão para se estabelecer novas maneiras de gestão num bem comum ditas mais eficientes" (Ostrom, 1990, p. 87). Além disso, se os usuários têm uma confiança prévia um no outro, os custos de monitorização diminuem. Destaca-se que as presenças de lideranças locais também reduzem esses custos.

Vale lembrar que muitas comunidades que lidam com recursos comuns são tradicionais e possuem uma relação religiosa e de respeito com a terra e com seus frutos. Este é um interessante aspecto que deve ser levado em consideração, talvez não como mais um dos oito princípios, mas, com certeza, como um elemento que dá à autogovernança (diferentemente do mercado ou do Estado) sua legitimidade. Isso porque "graças à íntima ligação com o meio ambiente no qual vivem, esses grupos mantêm seus territórios em condição tal que conservam (...) a sua biodiversidade e contribuem (...) para a manutenção da sustentabilidade de seus territórios" (Leroy, 2016, p. 7).

Nessas comunidades, o entendimento do recurso comum terra, por exemplo, vai muito além do seu valor econômico. A sociodiversidade agrária e as comunidades tradicionais "concebem a terra como um valor fora da órbita econômico-financeira, como território, um 'ser-objeto' fundamental para a vivência individual e coletiva do lugar político, (...) socioambiental e religioso da coletividade" (Melo, 2016, p. 40).

Esse é um entendimento mais politizado acerca dos recursos comuns. Correntes mais à esquerda tratam do comum como algo que não pode ser apropriado pelo homem por justamente ser a negação da propriedade, por se tratar de um direito. Segundo Dardot e Laval (2015), longe de se confundir com um objeto de propriedade, o bem comum exprime, acima de tudo, a dimensão do inapropriável:

Nada é em si ou por natureza "comum". Em última análise são as práticas sociais e somente elas que decidem sobre o caráter "comum" de uma coisa ou de um conjunto de coisas. Portanto, contra qualquer naturalismo ou essencialismo é preciso sustentar que é a atividade dos homens que torna uma coisa comum, guardando-a de qualquer lógica de apropriação e reservando-a para o uso coletivo (Dardot; Laval, 2015, p. 271).

Essa é uma corrente presente no Brasil que vem levantando frentes de luta por defesa de direitos (à terra, ao território, à água, aos direitos sociais e coletivos de maneira geral). Mais sobre esse movimento em defesa dos comuns será apresentado na seção "Novos recursos comuns no Brasil". 
Por hora, podemos sumarizar o que já foi dito anteriormente de uma maneira geral dizendo que a cooperação ocorre quando: a) os ganhos da cooperação futura superam o ganho imediato da deserção e devem ser suficientemente prováveis de acontecer; b) o horizonte temporal do jogo é incerto (lê-se jogo infinito); c) as estratégias de retaliação são críveis; e d) os jogadores devem valorizar mais o futuro para que os ganhos presentes da deserção não superem os ganhos futuros da cooperação (Seabright, 1993). É importante também que haja informações sobre os outros jogadores e que a escala dos participantes seja pequena (North, 1990).

Para fins didáticos, cabe salientar, ainda, um equívoco recorrente entre os leitores que começam a se desbravar nesse tema: bens comuns, por vezes, são confundidos com bens públicos. Isso ocorre porque ambos são bens não exclusivos, ou seja, os usuários têm acesso livre a esses recursos, não podendo ser impedidos de consumi-los, já que a privação do acesso é custosa ou, às vezes, impossível (Feeny et al., 1990).

A principal diferença reside no fato de que bens comuns são rivais, e os públicos não (Hall; Lieberman, 2003). Em outras palavras, o consumo de uma unidade de um bem comum como um recurso pesqueiro impede outro usuário de usufruí-lo (um mesmo peixe não pode ser pescado ao mesmo tempo por mais de um pescador). Por outro lado, em um bem público todos os usuários se beneficiam do recurso ao mesmo tempo. Um bom exemplo é a proteção da defesa nacional promovida pelo Exército (Mas-Colell et al., 1995).

\section{Recursos comuns tradicionais}

Recursos comuns tradicionais são aqueles recursos geridos pelo homem a partir dos quais a exclusão de beneficiários (através de meios físicos e institucionais) é altamente custosa, e a sua exploração por um agente diminui a disponibilidade para outro. Os recursos tradicionais apresentam regras comuns (formais ou informais) estabelecidas entre os seus agentes; são constituídos de uma história de interações humanas com o recurso, assim como apresentam sua trajetória ecológica própria (Hess, 2008).

Por mais que já amplamente investigados, esses recursos continuam a ser tema de diversos estudos, que atualmente servem de subsídios inclusive para políticas de desenvolvimento econômico local. Isso acontece por- 
que muitos governos federais vêm se aliando às comunidades gestoras de sistemas comuns como forma de promoção da sustentabilidade (manejo e proteção ambiental). A gestão comunitária dos recursos naturais é utilizada como política pública, por exemplo, por instituições internacionais de financiamento/fomento, por ONGs e pelas próprias administrações públicas locais, especialmente na África (Blaikie, 2006).

\section{Figura 1 Recursos considerados tradicionais}

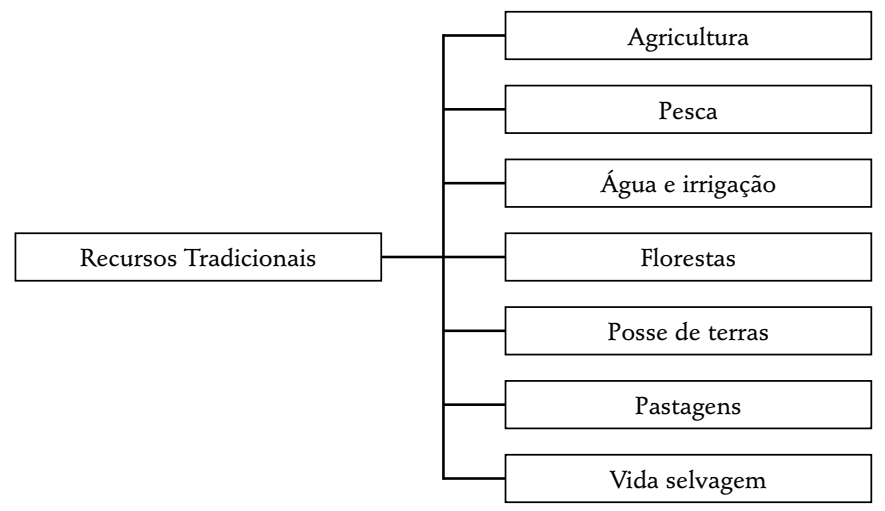

Fonte: Elaborado pelo autor baseado em Hess (2008).

De maneira geral, na literatura socioeconômica, podemos encontrar diferentes casos em que se documentam os benefícios de regimes de propriedade comum (gestão coletiva) que exploram recursos naturais. ${ }^{1}$ Nesse escopo, destaca-se um recente e interessante relatório intitulado "Assegurando direitos, combatendo as mudanças climáticas: como o fortalecimento dos direitos florestais comunitários mitiga as mudanças climáticas", realizado pelo World Resources Institute (WRI) e que investigou casos em mais de 14 países na América Latina, África e Ásia: Bolívia, Brasil, Colômbia, Equador, Guatemala, Honduras, Indonésia, México, Nepal, Nicarágua, Nigéria, Papua-Nova Guiné, Peru e Tanzânia.

A pesquisa constatou que as florestas (recurso comum) são menos desmatadas quando geridas por comunidades tradicionais através da autogovernança. Segundo o estudo, povos indígenas e comunidades locais podem evitar a destruição das florestas bem como as emissões de dióxido de Ostrom, 1990; Ostrom, Fenny, Pitch, 1990 e Hess, 2008. 
carbono associadas a essa prática (WRI, 2014). Descobriu-se que as taxas de desmatamento dentro das florestas comunitárias com reconhecimento legal e proteção governamental são bem menores do que em florestas fora dessas áreas (WRI, 2014).

$\mathrm{Na}$ Bolívia amazônica, por exemplo, as taxas de desmatamento foram seis vezes menores nas florestas em que os povos indígenas possuíam direitos legais, em comparação às florestas que não possuíam. Ainda segundo o mesmo estudo, nas reservas florestais da Guatemala, as florestas comunitárias legalmente reconhecidas sofreram apenas $0,02 \%$ de desmatamento em comparação com 0,41\% na Área Protegida da Reserva entre 1986 e 2007. Em outras palavras, houve cerca de 20 vezes menos desmatamento.

Constatou-se que, na região amazônica brasileira (de 2000 a 2012), a perda florestal foi de apenas $0,6 \%$ dentro das terras indígenas, enquanto fora delas foi de $7 \%$ (cerca de 11 vezes maior), e que 27 vezes mais emissões de CO2 foram produzidas fora das terras indígenas do que dentro delas (WRI, 2014). Outra estimativa sugere que as terras indígenas e as áreas protegidas pelo governo na Amazônia Brasileira poderiam impedir 27,2 milhões de hectares de desmatamento até 2050, uma área ligeiramente maior do que o Reino Unido, por exemplo (WRI, 2014).

Outra pesquisa, feita pelo BID (Banco Interamericano de Desenvolvimento) e pelo PNAS (Proceedings of the National Academy of Sciences), encontrou resultados consonantes, desta vez analisando a gestão florestal do Peru. A metodologia do estudo em questão consistiu em analisar, por imagens de satélite, determinadas áreas florestais antes e depois de a terra ter sido formalmente concedida às populações indígenas. Descobriu-se que a regularização de terras indígenas reduziu em $75 \%$ o desmatamento na floresta amazônica peruana nas localidades (PNAS, 2017), apontando que, para o caso peruano, o apoio à relação tradicional da terra traz benefícios para as comunidades e para o próprio governo.

Sabe-se que os governos federais, para protegerem suas florestas, despendem altos recursos em fiscalização e punição que muitas vezes são impraticáveis, uma vez que é demasiado custoso fiscalizar áreas florestais inteiras, sobretudo em lugares de difícil acesso. Dessa forma, uma solução para o comércio ilegal de madeira tem sido delegar essa função às comunidades indígenas, que já ocupam historicamente essas áreas, regularizando-as (PNAS, 2017). A regularização é muito importante porque, sem a devida posse da terra, os índios não podem reivindicar seus direitos quando 
a área é invadida. Por isso, assegurar direitos a essas comunidades não é só relevante, mas também se mostra uma solução mais barata e eficaz ao problema do desmatamento.

Entendidos esses aspectos, o presente artigo dedica-se agora a apresentar a realidade dos recursos comuns no Brasil, sobretudo a partir da ótica da autogovernança, uma vez que esta tem se mostrado uma corrente teórica e política de extrema relevância não só para o entendimento da problemática como também para a construção de sua solução.

\subsection{Recursos comuns tradicionais no Brasil}

Estudos empíricos de aspectos econômicos sobre a gestão de recursos comuns ainda são incipientes no país. ${ }^{2}$ Os primeiros estudos sobre gestão dos recursos comuns estão mais relacionados à área socioambiental; começaram a aparecer sistematicamente a partir da década de 1990 e descreveram sistemas de autogovernança em áreas florestais e em Unidades de Conservação. De maneira geral, tratava-se de estudos sociológicos sobre comunidades tradicionais ou de estudos ambientais sobre o manejo de determinadas espécies.

Sabe-se, entretanto, que o Brasil sempre foi um campo fértil de estudo para a área devido à relevância territorial da autogovernança e dos recursos comuns na região. Estima-se que, atualmente, cerca de $15 \%$ a $20 \%$ do território brasileiro esteja oficialmente fora do mercado, sendo caracterizado como áreas de gestão de (bens) comuns (Leroy, 2016). Esta é uma estimativa para os territórios ocupados por povos indígenas e comunidades tradicionais (extrativistas dos ecossistemas terrestres e das águas, setores do campesinato, quilombolas etc.) que podem ser muito menores do que o real porque muitas das terras comuns ainda não são reconhecidas (Leroy, 2016).

Com o intuito de compreender um pouco mais sobre a gestão dos recursos comuns no país, apresentam-se agora alguns estudos de caso atuais

2 Os principais estudos brasileiros a fazerem uma análise econômica sobre as diferentes maneiras de gestão dos recursos comuns foram aqueles sobre a pesca da lagosta no estado do Ceará (Diniz; Arrraes, 2001; Barroso, Sobel, 2009). Os estudos apresentam esquematizações matemáticas e gráficos econômicos que equacionam o estudo do nível ótimo da pesca da lagosta. Os autores analisam as possíveis maneiras de gestão do recurso (autorregulação, privatização, cotas, cobrança de taxas e agente externo), apontando os pontos fracos e os pontos fortes de cada uma delas. 
que identificaram tanto fatores limitantes quanto benefícios da autogovernança no Brasil. Estão listados todos os estudos encontrados na literatura brasileira que: a) trataram empiricamente do assunto, b) fizeram uma reflexão teórica consciente da questão da autogovernança, c) utilizaram-se do aparato metodológico de Elinor Ostrom ou de arcabouço teórico próximo a este, e que d) tenham sido publicados recentemente (a partir de 2000).

Os estudos estão espalhados por todo o território nacional (manejo de rios na bacia amazônica, fundos de pasto no Nordeste, reservas extrativistas litorâneas no Sul e Sudeste) e, em sua maioria, estão publicados com base no aparato de Elinor Ostrom e Douglas North. Os estudos em sua maioria são resultados de pesquisas de pós-graduação e estão sendo publicados em revistas ligadas aos mais diversos temas, como Administração Pública, Ciências Sociais, Desenvolvimento Sustentável etc.

\section{Tabela 3 Publicações empíricas sobre recursos comuns no Brasil}

\section{Publicação}

Rocha, 2017

Kefalás, 2016

Morimura, 2016

Caldasso, 2015

Caldasso, 2015

Dreyer; Nascimento, 2015

Silva et al., 2015

Gestão dos recursos naturais e governança dos comuns: um estudo da Reserva Extrativista de Canavieiras -

BA a partir das contribuições de Elinor Ostrom

Cooperativas em comunidades tradicionais pesqueiras: dois estudos de caso

Governança de recursos de base comum e capacidade adaptativa de comunidades de fundos de pasto

A interface entre economia e direito no debate sobre direitos de propriedade para recursos comuns: o caso das reservas extrativistas marinhas para a cogestão pesqueira no Brasil

Práticas de gestão de recursos comuns e alianças estratégicas: apoio à tomada de decisões na conservação socioambiental do litoral do Paraná

Estratégias de gestão coletiva de recursos naturais em assentamentos de reforma agrária da mesorregião da Mata Sul de Pernambuco - Brasil

Caldeira; Pierre, 2014

As relações econômicas e a gestão compartilhada de recursos comuns: o caso da pesca marinha em Pontal do Paraná, Sul do Brasil

Christmann; Stanziola, 2014

Gestão de bens comuns: tragédia dos comuns ou tragédia dos comunitários? Reflexões em torno da gestão de unidades de conservação de uso sustentável

De Souza et al., 2014

Melo, 2014
Governança de recursos comuns: bacias hidrográficas transfronteiriças Gestão comunitária de recursos comuns: o estudo de caso sobre a

Extração de Sarnambi, no Município da Raposa - MA 
Tabela 3 (continuação)

\begin{tabular}{|c|c|}
\hline Publicação & Título \\
\hline Pereira, 2013 & $\begin{array}{r}\text { Gestão de recursos comuns no entorno de áreas protegidas: } \\
\text { ação coletiva e desenvolvimento rural no sistema socioecológico (SES) } \\
\text { do Parque Nacional da Serra da Bodoquena - MS }\end{array}$ \\
\hline $\begin{array}{l}\text { Aguiar; Moreau; Fontes, } \\
2011\end{array}$ & $\begin{array}{l}\text { Histórico de criação da Reserva Extrativista Marinha de } \\
\text { Canavieiras (BA): posicionamentos antagônicos e gestão do território }\end{array}$ \\
\hline Castro; Mcgrath, 2010 & O manejo comunitário de lagos na Amazônia \\
\hline Santana; Fontes, 2010 & $\begin{array}{r}\text { Elementos de gestão local: a perspectiva de Elinor Ostrom aplicada ao } \\
\text { Parque Estadual da Ilha do Cardoso }\end{array}$ \\
\hline Barroso; Sobel, 2009 & $\begin{array}{l}\text { Os incentivos por trás da tragédia dos comuns: soluções e estudo do } \\
\text { caso da crise da pesca da lagosta no Ceará }\end{array}$ \\
\hline $\begin{array}{l}\text { Schmitz; Mota; Silva } \\
\text { Júnior, } 2009\end{array}$ & $\begin{array}{r}\text { Gestão coletiva de bens comuns no extrativismo } \\
\text { da mangaba no nordeste do Brasil }\end{array}$ \\
\hline Oviedo; Bursztyn, 2003 & $\begin{array}{l}\text { A quem confiamos os recursos comuns - Estado, comunidade ou } \\
\text { mercado? - Lições aprendidas com o manejo da pesca na Amazônia }\end{array}$ \\
\hline Diniz; Arraes, 2001 & Tragédia dos comuns e o exemplo da pesca da lagosta \\
\hline
\end{tabular}

Fonte: Próprio autor.

De acordo com a realidade brasileira observada nos estudos presentes na Tabela 3, percebe-se que as características institucionais mais presentes na agenda nacional e que corroboram o sucesso da autogovernança no Brasil estão relacionadas com: a) a presença de lideranças que coordenam as atividades dentro da comunidade, principalmente em comunidades tradicionais, b) a existência de acordos de uso dos recursos, e c) a presença de monitoramento pela própria comunidade.

Por outro lado, alguns princípios são poucos observados e a população encontra muitos obstáculos à sua realização. As populações sofrem com ameaças tais como problemas territoriais (conflitos de terra e falta de reconhecimento legal destas) e com atividades econômicas próximas que causam problemas ambientais diretos na comunidade. É recorrente também a fragilidade da delimitação dos recursos contra forasteiros e sua devida punição provida pela comunidade. Em outras palavras, a comunidade consegue monitorar as quebras dos acordos cooperativos, mas não consegue instrumentalizar sanções através de um poder de polícia.

Falta, portanto, um sistema governamental de proteção a essas comunidades nos mais diversos aspectos, entre os quais a proteção legal da terra e de limites claramente definidos é o mais importante. De maneira geral, 
a autogovernança no Brasil tem se mostrado eficiente na conservação dos recursos, entretanto, devido a pressões econômicas externas e internas, é necessário ajuda estatal para que algumas comunidades consigam se desenvolver, seja do ponto de vista da regularização territorial ou da defesa dos direitos de propriedade.

Corroborando os resultados encontrados por Ostrom (1990) para a literatura internacional, percebe-se que, para os casos brasileiros estudados, quanto mais dos princípios institucionais estavam presentes nas comunidades, maior era a chance de a autogovernança ser bem-sucedida. As experiências elencadas neste artigo apresentam diferentes performances cada uma, o que nos fornece interessantes insights sobre os entraves e a possibilidades para a autogovernança no país. Um estudo mencionado anteriormente se destaca pela atenção dada à sistematização dos princípios institucionais de Elinor Ostrom e pode ser mais especificamente comentado: O caso do Parque Estadual Ilha do Cardoso, em São Paulo.

O parque, localizado no sudeste do Brasil, possui 15.100 hectares e foi criado em 1962 pelo governo estadual com o objetivo de proteger e estudar a Mata Atlântica local. Os agentes envolvidos nesse sistema são 350 caiçaras, divididos em seis comunidades, e uma comunidade indígena que ocupou uma área deserta na ilha em 1992 e foi autorizada a lá permanecer. Hoje em dia, a população vive do ecoturismo (visitação de praias, golfinhos, trilhas, cachoeiras) e de atividades de pesca.

Nos primórdios do Parque, toda a gestão era chefiada pelo governo e todas as decisões eram resultado de uma decisão top-down. No entanto, após décadas de monopólio estatal na gestão do parque, implementou-se um Conselho Administrativo, que significou um importante avanço para incorporar a participação dos apropriadores nas decisões do parque. Atualmente, todas as decisões de política pública importantes no sistema são discutidas pelos moradores e, se necessário, votadas nas reuniões mensais desse Conselho Administrativo (CA).

O CA é composto de 16 cadeiras e presidido pelo diretor do parque. Cada uma das seis comunidades caiçaras tem uma representação nessas cadeiras. Outros assentos são ocupados por organizações não governamentais (ONGs) que lá operam, por representante da Comissão Pastoral da Terra e das esferas públicas que circundam o parque.

Devido à maior participação dos caiçaras no CA, aumentou-se o empoderamento da comunidade na gestão do parque e isso resultou em muitas 
consequências benéficas, incluindo o maior reconhecimento pelo Estado da capacidade de organização de seus moradores. Outros fatores de sucesso da autogovernança na comunidade incluem a sua pequena escala, a longa relação entre os participantes e a sua proximidade:

Com menos de 500 integrantes, a população do PEIC é capaz de negociar e se articular em torno de propostas concretas, organizando-se de forma efetiva e transmitindo segurança em suas ações, reduzindo o impacto negativo advindo de um eventual efeito carona (free rider) em virtude da maior proximidade dos participantes. Isso incentivou os órgãos do governo estadual responsáveis pelo PEIC a autorizar mais autonomia de gestão para as comunidades, confiando em sua capacidade e responsabilidade (Santana, Fontes, 2010, p. 12).

Outro importante incentivo à cooperação está na cultura das comunidades tradicionais, que fornece mecanismos baratos de resolução de conflitos através da presença de uma autoridade inquestionável ou figura de poder dentro da comunidade: "Os caiçaras se sentem representados por esta forma de liderança, que é percebida como uma orientação sábia e importante, não como tirania" (Santana; Fontes, 2010, p. 2).

Os autores também citam como essencial para a consecução da cooperação o histórico de convivência da população (superação de desconfianças) e a semelhança nos interesses dos agentes, para que convirjam em um acordo. Sobre esse aspecto, cabe relembrar que a resolução de conflitos pode ser uma atividade custosa, sobretudo quando há a necessidade de se levar as questões conflituosas a instâncias superiores (Ostrom, 1990).

Entendidas algumas das características dos recursos comuns tradicionais no Brasil, é válido expandir o debate de forma a entendermos como esses e outros problemas estão tendo soluções buscadas no campo teórico. Fala-se aqui de um movimento acadêmico e político em defesa dos denominados novos recursos comuns, uma esfera mais abrangente do que o conceito anterior. É válido lembrar, entretanto, que o termo "novo recursos comum" não deve predispor um entendimento de superação do conceito anterior.

Na verdade, estamos falando de uma mesma realidade, até dos mesmos recursos, só que agora de maneira mais abrangente na qual todo o sistema (agentes, natureza e sociedade) passa a ser visto como um recurso e não só o insumo natural físico. A próxima seção evidenciará como esse conceito dialoga com soluções atuais inteligentes para os mais diversos tipos de problemas e como, no Brasil, essa vertente vem tomando caráter politizado por defesa de direitos coletivos. 


\section{Novos recursos comuns}

Os "novos recursos comuns" apareceram na academia pela primeira vez em 1995 na conferência Reinventing the Commons, realizada pela International Association for the Study of Common Property (IASCP), (Hess, 2008). Desde então, seu crescimento vem sendo perceptível. Esses recursos englobam, entre outros, bens públicos anteriormente incapazes de serem estudados devido à falta de tecnologia da época. Trata-se de recursos cuja investigação exigia mais avanço acadêmico e tecnológico, tais como a internet, dados genéticos, espaço astral, mares profundos e espectros eletromagnéticos (Hess, 2008).

O caráter da rivalidade explicado anteriormente em relação aos recursos tradicionais agora não é mais tão presente, e a diferença entre bens públicos e bens comuns não é tão nítida: tem-se um conceito mais amplo, que está mais relacionado com a questão da coletividade do que propriamente à rivalidade ou a um recurso que tende a ser esgotado.

Entretanto, esta não é a única diferença dos novos recursos para os recursos tidos como tradicionais. As características de longa duração de um sistema de autogovernança não necessariamente se aplicam aos novos recursos comuns, uma vez que alguns deles são difusos e intangíveis, tais como o orçamento público ou regras de convívio em espaços comuns. Por isto, é difícil tentar encaixar nessa realidade aqueles oito princípios descritos por Ostrom. É preciso pensá-los de maneira diferente, ampla e multidisciplinar.

Dada essa transversalidade de escopos de investigação e de conceitos, existem formas distintas de se tratar o tema, algumas inclusive permeiam o campo político da luta de classes e da defesa de direitos comuns, conforme será melhor explicitado no final desta seção. Entretanto, para um primeiro contato e por se mostrar como uma opção mais didática, é interessante utilizarmos a abordagem teórica construída por Charlote Hess (2008). Segundo o entendimento da autora, esses recursos estão divididos em oito categorias: recursos culturais, de infraestrutura, de vizinhança, de mercado, médico e de saúde, globais e de informação/conhecimento. Essas categorias abrangem, ainda, diversos subtemas, apresentados na Figura 2, a seguir: ${ }^{3}$

3 Suprimiu-se o recurso comum de mercado, listado pela autora, por motivos de falta de exemplos empíricos que possam encontrar paralelo com a realidade brasileira atual. 
Figura 2 Novos recursos comuns

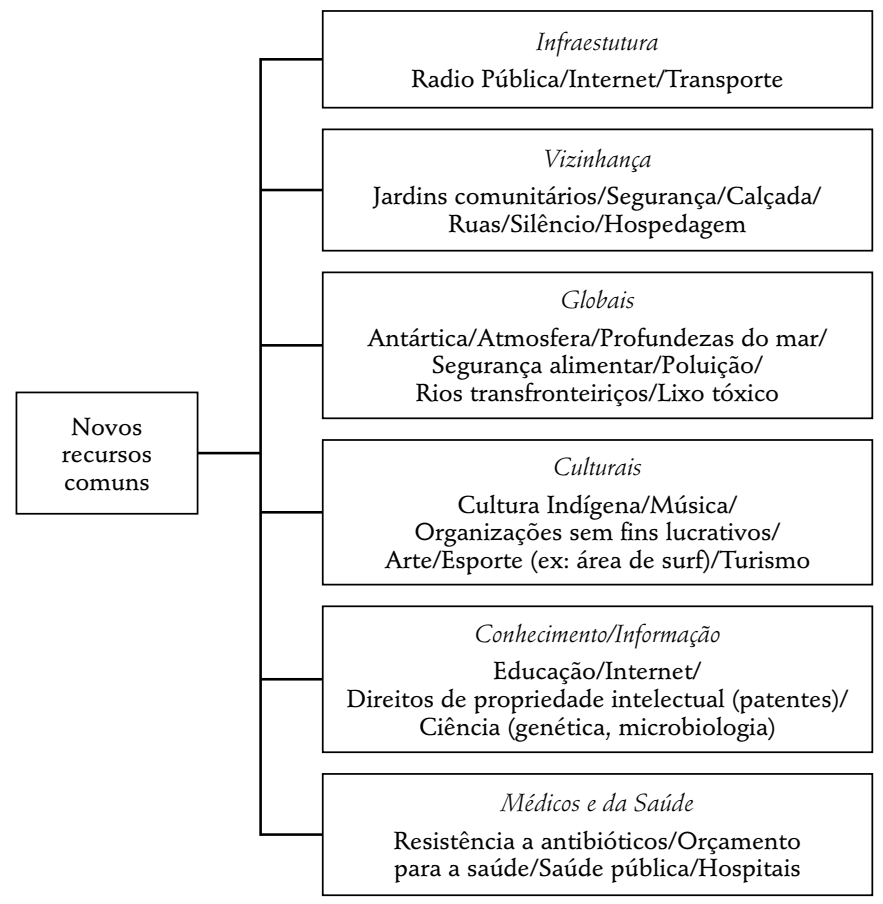

Fonte: Figura elaborada pelo próprio autor com base em Hess (2008).

Charlotte Hess, pesquisadora da Universidade de Indiana assim como Ostrom, estuda os recursos comuns há mais de 30 anos e organiza uma biblioteca sobre o tema. Em suas publicações, a autora explica detalhadamente cada um desses campos, apresentando todas as suas subdivisões e elencando inúmeros autores que estão tratando sobre os respectivos temas. ${ }^{4}$ Fez-se uma redução dessas subdivisões e das publicações citadas com o intuito de propiciar uma visão mais geral ao leitor.

Primeiramente, podemos falar dos recursos comuns de infraestrutura. Esses recursos estão ligados a sistemas providos pelo ser humano e são usufruídos por inúmeros usuários. Destacam-se: a) sistemas de transporte, tais como sistemas rodoviários, ferrovias, sistemas aéreos e portos; b) sistemas de comunicação, por exemplo, redes telefônicas e serviços postais; e c) serviços públicos básicos como escolas, esgotos etc. (Hess, 2008).

4 Charlotte em seu artigo "Mapping the new Commons" (2008) apresenta mais de 400 referências de artigos relacionados ao estudo dos novos recursos comuns e dos recursos tradicionais. 
Um exemplo é a tentativa de redução da velocidade em vias em Zurique (Suíça). O objetivo do experimento era conseguir a coordenação entre os agentes (motoristas locais) de modo a reduzir os acidentes através da conscientização da população em detrimento da imposição de uma legislação estatal, que, segundo o autor da pesquisa, muitas vezes não estava sendo eficiente (Gutscher et al., 2000).

Em segundo lugar, têm-se os recursos comuns de vizinhança, incluindo tanto a esfera urbana quanto a esfera rural. Incluem-se as questões de governança comunitária, de democracia, de capital social ${ }^{5}$ etc. Pessoas morando em espaços compartilhados (sejam vizinhos de um mesmo bairro, rua ou de uma cidade) ao passo que enfrentam problemas de convivência também possuem um fator aglutinador de força que pode ser o motor para a preservação ou proteção de um recurso local. Um exemplo é a tentativa de acordos de convivência entre moradores em um condomínio no Japão (West; Morris, 2003).

Os bens comuns globais são os novos recursos comuns mais estabelecidos na academia e também os que mais repercutem na mídia, sobretudo quando se trata de poluição e de mudanças climáticas. Esses recursos, portanto, dizem respeito a questões não locais, diferentemente dos recursos tradicionais. Englobam-se os tratados e conflitos internacionais, nos quais diferentes países objetivam o controle da temperatura global, por exemplo.

Os problemas relacionados a recursos globais recebem críticas por se acreditar que são incapazes de serem resolvidos, uma vez que são intangíveis. Essa crítica tem sido recorrente e está presente até mesmo na obra de Elinor Ostrom. A autora restringia seu conceito de recurso comum a um bem local porque sabia que o sucesso da autogovernança se dava justamente pela possibilidade de se estabelecerem limites bem definidos ao sistema (fronteiras, cercas, acordos). Entretanto, os atuais defensores dos recursos globais fazem sua réplica:

É possivel governar tais bens comuns como os oceanos e o clima? Permanecemos cautelosamente otimistas. Trinta e cinco anos atrás, parecia que a "tragédia dos bens comuns" era inevitável em todos os lugares (...) A pesquisa sistemática multidisciplinar, no entanto, mostrou que uma grande diversidade de sistemas de governança adaptativa tem administrado eficazmente estes recursos (Dietz et al., 2003).

5 Capital social: o agregado dos recursos efetivos ou potenciais ligados à posse de uma rede durável de relações mais ou menos institucionalizadas de conhecimento ou reconhecimento mútuo (Bourdieu, 1980). 
Continuando a descrição dos novos recursos comuns, têm-se os recursos culturais, aqueles que se relacionam à esfera pública de lazer e de patrimônio comum da humanidade. Um exemplo emblemático está nos esportes (subdivisão dos recursos culturais), mais especificamente o surfe. No surfe, quando os atletas (agentes) encontram um "pico" (um ponto onde há boas ondas) todos se dirigem para lá, congestionando o local a um ponto em que se impede a prática da atividade no local (Nazer, 2004). O objetivo dos "agentes" então, que seria pegar a onda, se vê comprometido pela superlotação do local. A resolução da "tragédia" passa por: a) acordos verbais, como o estabelecimento da ordem de quem surfa a onda primeiro, bem como o b) respeito a certas regras, como a prioridade aos mais velhos, por exemplo.

Os recursos de conhecimento/informação dizem respeito à disponibilização de conhecimento/patentes e são uns dos novos recursos com mais publicações na área. Recursos comuns de saúde referem-se à administração de hospitais e de orçamento na área, bem como questões mais técnicas como a proliferação de microrganismos. Estudos sobre bactérias, por exemplo, costumam denunciar o uso indiscriminado de antibióticos que acaba por gerar superbactérias. A falta de cuidado (moderação) em utilizar o recurso antibiótico tende a levar a sociedade a uma "tragédia" de superbactérias, que, no futuro, pode se tornar um problema de difícil solução (dada a inexistência de antibióticos para combater esses supermicrorganismos).

Trazemos na Tabela 4 algumas publicações nas esferas dos novos recursos comuns para entender como se relacionam com a tragédia dos comuns, bem como para apresentar referências para as pessoas que desejem se aventurar nessas áreas.

A intenção é demonstrar como algumas falhas de coordenação e a problemática dos recursos comuns estão presentes de maneira crescente na ciência e na vida das pessoas. Trata-se de uma tendência de cientistas em ler os problemas como frutos de um individualismo e de uma falta de coordenação entre agentes.

Por ser um tema recente, não existem ainda princípios bem definidos para lidar com a questão, sobretudo porque trata de temas muito diversos. Entretanto, pode-se perceber nesses relatos algumas semelhanças institucionais. $O$ ponto central estaria, em um momento inicial, na inexistência de leis ou contratos escritos que forcem determinado comportamento humano. Em outras palavras, num primeiro momento, busca-se o estímulo 
à cooperação, através da demonstração de seus benefícios e na aposta de contratos tácitos (regras informais estabelecidas no próprio escopo do problema como, por exemplo, os acordos verbais firmados entre surfistas ou regras entre motoristas em Zurique).

Tabela 4 Publicações (internacionais) sobre novos recursos comuns

\begin{tabular}{|c|c|c|}
\hline Publicação & Recurso comum & Tema \\
\hline $\begin{array}{l}\text { Pintassilgo; Albino } \\
2007\end{array}$ & Turismo de massa & $\begin{array}{r}\text { Tragédia dos comuns e a superlotação dos pontos } \\
\text { turísticos }\end{array}$ \\
\hline $\begin{array}{l}\text { Foster; Grundmann, } \\
2006\end{array}$ & Antibiótico & $\begin{array}{r}\text { Como o uso indiscriminado de antibiótico tem } \\
\text { fortalecido bactérias }\end{array}$ \\
\hline Lewis, 2004 & $\begin{array}{l}\text { Serviço de emer- } \\
\text { gência em hospitais }\end{array}$ & $\begin{array}{r}\text { Superlotação dos serviços de emergência e a queda } \\
\text { na qualidade dos mesmos }\end{array}$ \\
\hline $\begin{array}{l}\text { Neves-GracaGraça, } \\
2004\end{array}$ & $\begin{array}{r}\text { Ecoturismo de } \\
\text { visitação a baleias }\end{array}$ & $\begin{array}{l}\text { Como a estatização do serviço comunitário está } \\
\text { prejudicando o turismo em Açores - Portugal }\end{array}$ \\
\hline West; Morris, 2003 & Condomínio & $\begin{array}{l}\text { Importância da existência de leis para promoção da } \\
\text { ação coletiva em condomínio no Japão }\end{array}$ \\
\hline Nazer, 2004 & Esportes & $\begin{array}{l}\text { Lotação dos picos de surfe e as regras de convivência } \\
\text { entre surfistas em Los Angeles }\end{array}$ \\
\hline Chan; Costa 2005 & $\begin{array}{l}\text { Direitos de proprie- } \\
\text { dade intelectual }\end{array}$ & $\begin{array}{r}\text { Benefícios (e riscos) de tornar uma pesquisa um bem } \\
\text { comum (gratuito) }\end{array}$ \\
\hline Little, 2005 & $\begin{array}{r}\text { Infraestruturas de } \\
\text { engenharia }\end{array}$ & $\begin{array}{r}\text { Quem está disposto a arcar com os custos de uma } \\
\text { obra que beneficiará a todos }\end{array}$ \\
\hline $\begin{array}{l}\text { Wellenius; Neto, } \\
2007\end{array}$ & Ondas de rádio & $\begin{array}{l}\text { Problema nas telecomunicações devido ao excesso de } \\
\text { transmissores de onda de rádio }\end{array}$ \\
\hline $\begin{array}{l}\text { Gutscher et al., } \\
2000\end{array}$ & Trânsito & $\begin{array}{r}\text { Redução de velocidade e congestionamento de } \\
\text { rodovias em Zurique }\end{array}$ \\
\hline
\end{tabular}

Fonte: Tabela formada a partir das publicações presentes em Hess (2008), de acordo com a relevância de cada artigo para a subárea temática.

Num segundo momento, caso a cooperação não ocorra, passe-se para a necessidade de imposição de certas leis para coordenar a ação humana (como no caso da administração de condomínio no Japão). Entretanto, de uma maneira geral, pode-se dizer que os problemas divergem bastante quanto à natureza e seria bem difícil tentar achar uma lista de princípios convergentes. O que fica clara é a tentativa de resolução um problema comum (falha de coordenação entre agentes que geram conflitos das mais diversas naturezas e atingem uma determinada população) de maneira conjunta, sabendo que, coletivamente, a solução será menos custosa e mais eficiente. 
Do ponto de vista nacional, observam-se setores da sociedade (muitos deles representados por comunidades tracionais, locais e por movimentos sociais relacionados à moradia, à reforma agrária etc.) que cada vez mais reconhecem bens comuns como um patrimônio que deva ser defendido, como um direito. Pode-se, então, falar em um movimento a favor dos novos recursos comuns (ainda estrangeiro, mas que já começa a se estruturar nacionalmente), a favor de reivindicar esses recursos como públicos, como patrimônio ou como acessível às determinadas comunidades (Hess, 2008). No caso brasileiro, trata-se, antes de tudo, de movimentos de resistência ${ }^{6}$. Isso porque a lógica de privatização dos espaços comuns e dos recursos naturais com a finalidade da maximização do lucro expulsa e marginaliza inúmeras comunidades tradicionais.

Frente a essa mercantilização e à privatização da natureza, o debate político-acadêmico sobre os bens comuns no país vem ganhando força, com publicações em diversas searas do conhecimento. Entretanto, por não se tratar do escopo principal do artigo, essa produção não será apresentada mais detalhadamente. Importante é saber que o Brasil começa a dar passos para se organizar em torno da luta pelos novos recursos comuns, ainda que o termo "novo" não seja utilizado pela academia brasileira e ainda que a produção bibliográfica sobre esse tema esteja dispersa em diferentes frentes. Acredita-se, portanto, na força e na necessidade da simbiose entre pesquisadores e lideranças sociais para o prosseguimento da causa de maneira mais efetiva perante a sociedade.

\section{Considerações finais}

Desde a principal publicação de Ostrom, o estudo da autogovernança e dos recursos comuns se expandiu bastante. O próprio conceito de recursos comuns se modificou, englobando atualmente tanto recursos ditos tradicionais quanto os novos recursos comuns. A evolução do campo de estudo ampliou a discussão para inúmeros problemas ambientais, econômicos e sociais contemporâneos, aumentando sua relevância para a ciência.

6 Fala-se em resistência porque a busca por direitos ao reconhecimento de suas terras e culturas é uma vertente de luta judicial e física no país. Em 2014, foram registrados 138 assassinatos e 135 suicídios indígenas e CIMI (2014). No mesmo ano, 12.188 famílias camponesas foram despejadas, ocorrendo ainda 36 assassinatos e 56 tentativas de assassinato MEDEIROS (2015). 
Incluem-se aí debates que vão desde o uso da internet, o congestionamento de carros e existência de superbactérias até problemas de coordenação de interesses de vizinhos em um condomínio.

Tendo em vista tal evolução, este artigo tenta contribuir com o entendimento do tema ao dissertar sobre a atualidade do estudo sobre recursos comuns tanto fora quanto dentro do país, trazendo à tona novas discussões que problematizam realidades cotidianas. Se internacionalmente a questão ganhou muita repercussão e se expandiu por diversos países, percebe-se que o estudo da autogovernança no Brasil começa a se estruturar mais recentemente. De maneira geral, cientistas de áreas ambientais e sociais é que vêm dando fôlego à questão.

Alguns estudos nacionais encontram paralelo com a obra de Ostrom, nos quais se pode verificar a descrição de alguns dos princípios institucionais propostos pela autora. Os princípios mais presentes nas comunidades brasileiras e que podem ser considerados como principais motivos para o sucesso das autogovernanças estudadas são a presença de líderes locais que diminuem custos na resolução de conflitos e a existência de acordos que ditam regras de apropriação e uso dos recursos comuns (exemplo, caso da autogovernança na Ilha do Cardoso). Por outro lado, a incidência de fatores externos (como lutas fundiárias) e a falta de reconhecimento por parte do Estado brasileiro dos direitos das comunidades tradicionais (sobretudo territoriais e outros direitos de propriedades) são importantes entraves ao funcionamento da cooperação. $O$ problema da inviabilidade do sistema cooperativo surge por incompatibilidades entre os diferentes elementos do sistema, e quando a resolução desses antagonismos não pode ser implementada sem custos de transação proibitivos (Herscovici, 2013).

Para além disso, a fragilidade de algumas de comunidades tradicionais perante o poder externo do mercado ou de forasteiros faz com que a "terceira via" necessite de uma ajuda institucional do governo. Em alguns casos, quando o estado aparece como interventor, essa ajuda traz mais prejuízos do que benefícios. Entretanto, quando as estruturas da própria comunidade não conseguem se proteger desses conflitos internos ou de ameaças externas, faz-se necessária a presença do poder de polícia estatal.

Do ponto de vista político e mais atual, setores organizados da sociedade vêm traçando estratégias coletivas para fortalecer e preservar os sistemas de recursos comuns, a partir de um conceito de recursos comuns mais 
amplo e de uma prática voltada à luta política. Destacam-se movimentos em prol da agricultura familiar, do direito à moradia e ao acesso à água.

Percebe-se então que a academia socioambiental, as comunidades tradicionais e os movimentos sociais se caracterizam como as três frentes de defesa dos recursos comuns no país, de maneira crescentemente organizada, a partir do compartilhamento de experiências e pesquisas, em uma realidade em que o político se mistura cada vez mais com o científico, e vice-versa.

\section{Referências}

AGUIAR, P.; MOREAU, A.; FONTES, E. Histórico de criação da Reserva Extrativista Marinha de Canavieiras (BA): posicionamentos antagônicos e gestão do território. In: ENCONTRO BAIANO DE GEOGRAFIA/ SEMANA DE GEOGRAFIA DA UESB, 8. Anais... Vitória da Conquista - BA, 2011.

BALLESTEROS, H.; ALCOFRADO, I. A tragédia dos commons e o direito de propriedade: Com Hardin, além de Hardin. In: ENCONTRO DA SOCIEDADE BRASILEIRA DE ECONOMIA ECOLÓGICA, Cuiabá, 2009.

BARROSO, R.; SOBEL, T. Os incentivos por trás da tragédia dos comuns: soluções e estudo do caso da crise da pesca da lagosta no Ceará. In: CONGRESSO DA SOBER - Agropecuária, Meio-Ambiente e Desenvolvimento Sustentável, 47., 2009, Porto Alegre, RS.

BOURDIEU, Pierre. Le capital social: notes provisoires. Actes de la recherche en sciences sociales, v. 31, n. 1, p. 2-3, 1980.

BLAIKIE, P. Is small really beautiful? Community-based natural resource management in Malawi and Botswana. World Development, 34(11), 1942-1957, 2006.

CALDASSO, L. A interface entre economia e direito no debate sobre direitos de propriedade para recursos comuns: o caso das reservas extrativistas marinhas para a cogestão pesqueira no Brasil. Tese (Doutorado) - Universidade Federal do Rio de Janeiro, 2015.

CALDEIRA, G. A. PIERRE, N. As relações econômicas e a gestão compartilhada de recursos comuns: o caso da pesca marinha em Pontal do Paraná, Sul do Brasil. Desenvolvimento e Meio Ambiente, 32, 2014.

CASTRO, F. D.; McGraph, D. O manejo comunitário de lagos na Amazônia. Parcerias Estratégicas, 6(12), 112-126, 2010.

CHAN, L.; COSTA, S. Participation in the global knowledge commons: challenges and opportunities for research dissemination in developing countries. New Library World, 106(3/4), 141-163, 2005.

CHIRSTMANN, L.; STANZIOLA, R. Gestão de bens comuns: tragédia dos comuns ou tragédia dos comunitários? Reflexões em torno da gestão de unidades de conservação de uso sustentável, 2014. 
CIMI,Conselho Indigenista Missionário. Relatório Violência contra os Povos Indígenas no Brasil - Dados de 2014 Coordenação da pesquisa: Lúcia Helena Rangel.

COASE, R. The nature of the firm. New Series, v. 4, n. 16, p. 386-405, 1937.

CLARK, C. Mathematical Bioeconomics: The Optimal Management of Able Resources. New York: John Wiley, 1976.

DALES, J. H. Pollution, Property, and Prices: An Essay. In: Policy-making and Economics. Toronto: University of Toronto Press, 1968.

DARDOT, P.; LAVAL, C. Propriedade, apropriação social e instituição do comum. Tempo Soc. [on-line], 2015, v. 27, n. 1, p. 261-273.

DASGUPTA, Partha S.; HEAL, Geoffrey M. Economic theory and exhaustible resources. Cambridge University Press, 1979.

DE SOUZA et al. Governança de recursos comuns: bacias hidrográficas transfronteiriças. Revista Brasileira de Política Internacional, v. 57, n. 2, 2014.

DIETZ, T.; OSTROM, E.; STERN, C. The struggle to govern the commons. Science, 302(5.652), 1907-1912, 2003.

DINIZ, M. B.; ARRAES, R. de A. Tragédia dos comuns e o exemplo da pesca da lagosta: abordagens teóricas. In: ENCONTRO NACIONAL DE ENGENHARIA DE PRODUÇÃO, 21., 2001, Salvador. Anais... Salvador: Enegep, 2001.

DREYER, M.; NASCIMENTO, D. Práticas de gestão de recursos comuns e alianças estratégicas: apoio à tomada de decisões na conservação socioambiental do litoral do Paraná. In: SIMPÓSIO NACIONAL DE CIÊNCIA, TECNOLOGIA E SOCIEDADE, 2015.

FEENY, David et al. The tragedy of the commons: twenty-two years later. Human ecology, v. 18, n. 1, p. 1-19, 1990.

FES - FOUNDATION OF ECOLOGIAL SECYRITY. Vocabulary Commons, 2011.

FOSTER, K. R.; GRUNDMANN, H. Do we need to put society first? The potential for tragedy in antimicrobial resistance. Plos Med, 3(2), e29, 2006.

GUTSCHER, H.; KELLER.,C..; MOSLER, H. J. Roads as new common pool resources, speed reduction as a public good - Two case studies in organizing large-scale collective action. In: Available: CD: BIENNIAL CONFERENCE OF THE INTERNATIONAL ASSOCIATION FOR THE STUDY OF COMMON PROPERTY (IASCP), $8^{\text {th }}$., (v. 82), Indiana University, Bloomington, Indiana, 2000.

HALL, R.; LIEBERMAN, M. Microeconomia: princípios e aplicações. São Paulo: Pioneira Thomson Learning, 2003.

HARDIN, G. The Tragedy of the Commons. Science, v. 162, pp. 1.243-1.248, 1968.

HERSCOVICI, A. Escolha coletiva, governança e direitos de propriedade: uma análise econômica dos commons. Nova Economia, v. 23, p. 1, 19 set. 2013.

HESS, C. Mapping the New Commons, presented at "Governing Shared Resources: Connecting Local Experience to Global Challenges". In: BIENNIAL CONFERENCE OF THE INTERNATIONAL ASSOCIATION FOR THE STUDY OF THE COMMONS, $12^{\text {th }}$., University of Gloucestershire, Cheltenham, England, July 14-18, 2008.

HOTELling, H. The Economic of Exhaustible Resources. The Journal of Political Economy, 
v. 39, p. 2, p. $137-175,1931$

KANDEL, E.; LAZEAR, E. Peer pressure and partnerships. Journal of Political Economy, 100(4), 801-817, 1992.

KEFALÁS, H. Cooperativas em comunidades tradicionais pesqueiras: dois estudos de caso. Tese (Doutorado) - Universidade de São Paulo, 2016.

LEROY, J. P. Mercado ou bens comuns? O papel dos povos indígenas, comunidades tradicionais e setores do campesinato diante da crise ambiental. Rio de Janeiro, RJ: Fase, 2016.

LEWIS, R. J. Academic Emergency Medicine and the "Tragedy of the Commons". Academic Emergency Medicine, 11(5), 423-427, 2004.

LITTLE, R. G. Tending the infrastructure commons: ensuring the sustainability of our vital public systems. Structure and Infrastructure Engineering, 1(4), 263-270, 2005.

MAS-COLELL, Andreu et al. Microeconomic theory. New York: Oxford university press, 1995.

MEDEIROS, L. S. Conflitos fundiários e violência no campo. In: CPT. Conflitos no Campo - Brasil 2014 [Coordenação: Antônio Canuto, Cássia Regina da Silva Luz, Edmundo Rodrigues Costa[Goiânia]: CPT Nacional - Brasil, 2015.

MELO, A. A. Gestão comunitária de recursos comuns: o estudo de caso sobre a Extração de Sarnambi, no Município da Raposa -MA. 2014. (Dissertação em Desenvolvimento Socioespacial e Regional) - Universidade Estadual do Maranhão 2014. (Embrapa Cocais)

MELO, J. Direito à participação popular no licenciamento ambiental brasileiro: análise do projeto santa Quitéria de mineração de urânio e fosfato. Dissertação. 2016. (Mestrado em Direito Constitucional) - Universidade Federal do Ceará, Fortaleza, 2016.

MORIMURA, M. Governança de Recursos de Base Comum e capacidade adaptativa de comunidades de Fundos de Pasto. Tese de Doutorado. Brasília: Universidade de Brasília, 2015.

MUELLER, C. Os economistas e as relações entre o sistema econômico e o meio ambiente. Brasília: Editora UnB, 2007.

NAZER, D. The Tragicomedy of the Surfers' Commons. Deakin Law Review, v. 9, n. 2: 654713, 2004.

NEVES-GRAÇA, K. Revisiting the tragedy of the commons: Ecological dilemmas of whale watching in the Azores. Human Organization, 63(3), 289-300, 2004.

NORTH, D. Institutions, Institutional Change and Economic Performance. Cambridge: Cambridge University Press, 1990.

OLSON, M. The Logic of Collective Action: Public Goods and the Theory of Groups 1965.

OVIEDO, A.; BURSZTYN, M. A quem confiamos os recursos comuns-estado, comunidade ou mercado? Lições aprendidas com o manejo da pesca na Amazônia. Sociedade e Estado, 18(1-2), 177-198, 2003.

OSTROM, V.; FENNY, D.; PICHT, H. Institutional Analysis and Development: Rethinking the Terms of Choice. Rethinking Institutional Analysis and Development. In: OSTROM, V.; FEENY, D.; PICHT, H. (Ed.). International Centre for Economic Growth, USA, 1990.

OSTROM, E. Governing the commons. The evolution of institutions for collective action. Cam- 
bridge: Cambridge University Press, 1990.

OSTROM, E. Design principles and threats to sustainable organizations that manage commons. In: Paper for electronic conference on Small Farmer's Economic Organizations, organized by Julio A. Berdegue. Santiago, Chile, March. 1999.

PEREIRA, M. de A. Gestão de recursos comuns no entorno de áreas protegidas: ação coletiva e desenvolvimento rural no sistema socioecológico (SES) do Parque Nacional da Serra da Bodoquena - MS. 2013. Tese (Doutorado em Desenvolvimento Rural) - Universidade Federal do Rio Grande do Sul, Faculdade de Ciências Econômicas, 2013.

PINTASSILGO, S. Tragedy of the commons in the tourism accommodation industry. Tourism Economics, 13(2), 209-224, 2007.

PNAS - Proceedings of the National Academy of Sciences. Titling indigenous communities protects forests in the peruvian Amazon. 2017.

ROCHA, A. Gestão dos recursos naturais e governança dos comuns: um estudo da Reserva Extrativista de Canavieiras (BA) a partir das contribuições de Elinor Ostrom. 2017. Dissertação (Mestrado em Economia Regional e Políticas Públicas Ilhéus) - Universidade Estadual de Santa Cruz, 2017.

SANTANA, V.; FONTES, J. Elementos de gestão local: a perspectiva de Elinor Ostrom aplicada ao Parque Estadual da Ilha do Cardoso. In: ENCONTRO DE ADMINISTRAÇÃO PÚBLICA, Vitória, 2010.

SCHMITZ, H.; MOTA, D.; SILVA JÚNIOR, J. Gestão coletiva de bens comuns no extrativismo da mangaba no nordeste do Brasil. Ambiente \& Sociedade, Campinas v. XII, n. 2, p. 273-292, jul./dez. 2009.

SEABRIGHT, Paul. Managing local commons: theoretical issues in incentive design. Journal of economic perspectives, v. 7, n. 4, p. 113-134, 1993.

SILVA, R. V. et al. Estratégias de gestão coletiva de recursos naturais em assentamentos de reforma agrária da mesorregião da Mata Sul de Pernambuco - Brasil. Acervo On-line de Midia Regional. 2015.

STIGLITZ, J. Incentives and risk sharing in sharecropping. Review of Economic Studies, v. 41, n. 2, p. 219-255, 1974

TUCKER, Albert W.; STRAFFIN JR, Philip D. The mathematics of Tucker: A sampler. The Two-Year College Mathematics Journal, v. 14, n. 3, p. 228-232, 1983.

VOINEA, A. Joseph Stiglitz proposes co-op models as an alternative to trickle-down economics. Cooperative News. 12 de out de 2016.

WELLENIUS, B.; NETO, I. The radio spectrum: opportunities and challenges for the developing world. Info, 8(2), 18-33, 2006.

WEST, M. D.; MORRIS, E. M. The tragedy of the condominiums: Legal responses to collective action problems after the Kobe earthquake. The American Journal of Comparative Law, 51(4), 903-940, 2003.

WRI - World Resource Institute. Assegurando direitos, combatendo as mudanças climáticas: como o fortalecimento dos direitos florestais comunitários mitiga as mudanças climáticas. Washington, 2014. 


\section{Sobre os autores}

MateusCesar-mateuscesarb@hotmail.com

Universidade Estadual de Campinas, Campinas, São Paulo, Brasil. ORCID: https://orcid.org/0000-0002-3195-4582.

IvetteLuna-iluna@unicamp.br

Universidade Estadual de Campinas, Campinas, São Paulo, Brasil. ORCID: https://orcid.org/0000-0002-5304-5523.

ElliePerkins-esperk@yorku.ca

York Univeristy, Toronto, Canadá.

ORCID: https://orcid.org/0000-0002-6474-0142.

\section{Sobre 0 artigo}

Recebido em 22 de maio de 2018. Aprovado em 27 de fevereiro de 2019. 